\title{
AVALIAÇÃO DA MONENSINA SÓDICA EM VACAS LEITEIRAS
}

\author{
O. CAMPOS NETO'; A.A. RAMOS'; M.J. ESCOBAR ${ }^{2}$; J.A. DALANESP; C.H.W. DE BEM ${ }^{4}$
}

'Faculdade de Medicina Veterindna e Zootecnia-UNESP - CEP: 18618-000 - Botucatu,SP.

'Elanco Quimica Ltda, Av. Morumbı, 8264 - CEP: 04703-002 - São Paulo, SP.

'Zootecnista - FMVZUNESP, Botucatu,SP.

¿Pós-Graduando-FMVZJNESP, Botucatu,SP.

RESUMO: Utilıaram-se quinze vacas da raça Holandesa, submetidas a três tratamentos: T1-controle, T2-monensina sodica 300 mg/animal/dia, T3-monensina sódica 225 mg/animal/dia. A produçăo de lelte, consumo de raçăo e o peso dos animais foram mensurados, juntamente com a avaliaç̋o da condiç̋lo corporal. Após o periodo experimental de 112 dias, evidencioun-se aumento na produçăo de leite de 13,5\% e 10\% (T2) em relaço a T1 e T3 respectivamente. Houve reduçăo de consumo de raç̆o de $4,5 \%$ (T2) e $3 \%$ (T3) em relaç̧o ao controle.

Descritores: produçio de leite, ionóforo

\section{EVALUATION OF SODIUM MONENSIN IN DAIRY COWS}

\begin{abstract}
Milk and feed consumption were monitored in fifteen Holstein cows divided in 3 groups: T1 (control), T2 (sodium monensin - $300 \mathrm{mg} / \mathrm{head}$ ) T3 (sodium monensin - $225 \mathrm{mg} / \mathrm{head}$ ). After an experimental period of 112 days, there were $13.5 \%$ and $10 \%$ (T2) increase in millk production as compared to the control and T3 respectively, and also a feed intalce reduction $4.5 \%$ (T2) and $3 \%$ (T3) as compared to the control.
\end{abstract}

Key Words: milk production, lonophore

\section{INTRODUÇĀO}

A utilização de aditivos na alimentação animal, significa uma forma de incrementar a produção de proteína de alto valor biológico para uma população humana em constante crescimento. É uma medida eficaz para aumentar a produção e rentabilidade das explorações pecuárias.

A manipulação e modificação da fermentação ruminal no sentido de melhorar o desempenho animal, tem sido objetivo de muitas pesquisas em diversas espécies de ruminantes. Dentre os compostos que agem melhorando a qualidade ou a quantidade de nutrientes disponiveis para absorção pelo trato gastrintestinal, e com isso melhorando o desempenho dos ruminantes, destacam-se os ionóforos. Sendo a monensina sódica o ionóforo mais intensivamente utilizado em dietas de ruminantes.

A monensina é o ionóforo mais conhecido até o momento, quanto aos seus efeitos sobre o padrão de fermentação ruminal e suas consequências na produção animal. Originalmente a monensina foi usada como coccidiostático em raçő́es de aves. É um composto produzido por linhagens de Streptomyces cinnamonensis, possuindo peso molecular elevado, é tóxica a muitas bactérias, protozoários, fungos e alguns organismos superiores, sendo por isso classi- ficada como um antibiótico (RUSSEL \& STROBEL, 1989).

Em estudo realizado por SCHELLING (1984), foi proposto sete modos de ação, através dos quais, monensina, melhora o desempenho de ruminantes: 1) modificação na produção de ácidos graxos voláteis, 2) alteração no consumo de alimentos, 3) alteração na produção de gases, 4) modificação na digestibilidade dos alimentos, 5) alteração no enchimento do rúmen e na taxa de passagem, 6) alteração na utilização de proteína, 7) Outros modos de ação. Os efeitos da monensina sobre a fermentação numinal são devido à mudanças na ecologia ruminal (CHEN \& WOLIN, 1979). As bactérias gram-positivas produtoras primárias de acetato, butirato, $\mathrm{H}_{2}$ e formato, são inibidas em presença de monensina. $E$ as espécies gram-negativas, muitas das quais produzem succinato que é o precursor do propionato são as mais resistentes (BERGEN \& BATES, 1984). As bactérias metanogênicas são diretamente inibidas, através da utilização de $\mathrm{H}_{2}$ metabólico para a produção de propionato por outras bactérias, diminuindo assim a produção de metano (BERGEN \& BATES, 1984).

Vários ionóforos (monensina, lasalocida, salinomicina, nasarina) tem sido fornecidos a bovinos de corte, sendo a eficácia desses compostos considerada similar. Nas dietas que contém níveis ele- 
vados de carboidratos rapidamente fermentáveis, os ionóforos geralmente deprimem o consumo de alimento, porém o ganho de peso não é diminuído e a conversão alimentar é melhorada. Quando bovinos são alimentados com dietas contendo consideráveis quantidades de forragem, os ionóforos não reduzem o consumo, a conversão alimentar é aumentada, porém, com o aumento do ganho de peso (NAGARAJA et al., 1981).

CAMPOS NETO et al. (1983) estudaram o efeito da adiçăo de monensina $(100 \mathrm{mg})$ em dietas de novilhas da raça holandesa, recebendo $33 \%$ de concentrado e $67 \%$ de volumoso, verificaram que houve aumento de ganho de peso semelhante ao tratamento testemunha, porém com uma redução no consumo de ração em $10 \%$ e melhora na eficiência alimentar. GOODRICH et al. (1984) analisaram 228 ensaios que envolveram 11.274 bovinos utilizando dietas ricas em grãos, concluíram que a monensina aumentou o ganho de peso em $1,6 \%$, reduziu o consumo $\mathrm{em} 6,4 \%$, melhorando a conversão alimentar em 7,5\%. SPROTT et al. (1981) revisando os trabalhos sobre o efeito dos ionóforos em vacas de cria e novilhas para reposição, recebendo dietas à base de forragens, verificaram efeitos positivos desses agentes sobre o ganho de peso, conversão alimentar, intervalo do parto ao primeiro cio, redução na idade a puberdade e nenhum efeito prejudicial sobre a fertilidade em machos e fêmeas.

Poucos estudos são encontrados na literatura analisando a adição de ionóforos em dietas de vacas em lactação, e seus efeitos sobre a produção e composição do leite. RANDEL \& ROUQUETE (1976) registraram que monensina $(200 \mathrm{mg} / \mathrm{dia})$ reduziu em $12,4 \%$ a necessidade alimentar de vacas de corte em lactação. A adição de monensina não influenciou a produção e a composição do leite (RANDEL \& ROUQUETE, 1976; LEMENAGER et al., 1978), mas aumentou o ganho de peso de bezerros criados com as vacas suplementadas com monensina (LEMENAGER et al., 1978). BROWN
\& HOGUE (1985) administraram 33 e $18 \mathrm{ppm}$ de monensina a cabras em lactação. A produção de leite não foi alterada, porém houve reduçăo de $5 \%$ a $15 \%$ no conteúdo de gordura e $10 \%$ de aumento no conteúdo de proteina do leite dos animais que receberam $33 \mathrm{ppm}$ de monensina. OLIVEIRA et al. (1992) estudaram a utilização da monensina na alimentação de vacas leiteiras da raça holandesa com produção média de 32,86 litros por dia, e verificaram que a dose de $300 \mathrm{mg}$ de monensina/vaca/dia, apresentou melhor resposta em relação a produção de leite. Para constatar a presença de resíduos de monensina no leite, DONOHO (1984) forneceu $300 \mathrm{mg} /$ dia de monensina $\left[C_{14}\right]$ em dieta de novilhas antes da parição. Após a parição, o colostro continha menos do que $0,23 \mathrm{ppm}$ baseando-se na radioatividade e em amostragens posteriores, apresentaram não mais do que $0,01 \mathrm{ppm}$. A partir desses resultados demonstrou-se que o efeito residual da monensina no leite não é um problema, podendo esse ionóforo ser usado em rações de vacas em lactação.

De modo geral, os efeitos da utilização de monensina sódica em dietas de vacas em lactação tem levado as seguintes observações: diminuição no teor de gordura do leite e quanto a produção, há evidências de melhora. Porém, a maioria dos trabalhos dizem respeito a adição de monensina em dietas de bovinos de corte, havendo poucas referências de seus efeitos em seu uso na alimentação de vacas leiteiras. Assim, torna-se necessário o estudo da ação desse ionóforo sobre o desempenho de vacas leiteiras, através do estabelecimento de dosagens ideais e caracterizar seus efeitos sobre a produção de leite.

\section{MATERIAL E METODOS}

$O$ presente experimento foi realizado na Fazenda Pinheiro, produtora de leite tipo B, localizada no municipio de Botucatu, SP. Foram utilizadas 15 vacas da raça holandesa, com peso médio de $500 \mathrm{~kg}$,

TABELA 1. Composição bromatológica de concentrado e forragens.

\begin{tabular}{lccrcccc}
\hline \hline & \multicolumn{7}{c}{$\%$} \\
\cline { 2 - 8 } & MS & PB & FB & EE & Ca & P & NDT $^{*}$ \\
\hline Concentrado & 89 & 20 & 4,91 & 3,15 & 1,18 & 0,75 & 72 \\
Silagem de milho & 34 & 8,0 & 25 & 3,1 & 0,23 & 0,22 & 70 \\
Feno de capim & 88 & 7,8 & 32,5 & 2,5 & 0,38 & 0,20 & 56 \\
coast-cross & & & & & & & \\
\hline \hline
\end{tabular}

* NDT - Calculado segundo KEARL (1982). 
separadas em 3 lotes de acordo com a produção de leite da lactação anterior, número de lactações e número de dias de lactação. Os animais foram mantidos em 3 piquetes e tiveram a sua disposição: silagem de milho, feno de capim Coast-cross, concentrado, sal mineral e água.

A análise bromatológica do concentrado e forragem está apresentada na TABELA 1, segundo ASSOCIATION OF OFFICIAL AGRICULTURAL CHEMISTS (1965). A composição do concentrado está apresentado na TABELA 2.

A fase de adaptação a monensina sódica foi de 28 dias, antes do parto e a fase experimental foi de 112 dias após o parto. Nos primeiros 14 dias de adaptação, a dosagem de monensina sódica foi de $150 \mathrm{mg} / \mathrm{cab} / \mathrm{dia}$ para o lote T2 e $112,5 \mathrm{mg} / \mathrm{cab} / \mathrm{dia}$ para o lote T3. Após a fase de adaptação, a dosagem foi de $300 \mathrm{mg} / \mathrm{cab} / \mathrm{dia}$ e $225 \mathrm{mg} / \mathrm{cab} / \mathrm{dia}$, respectivamente para o lote T2 e T3. O veículo para a administração individual das dosagens de monensina sódica (300 e $225 \mathrm{mg} / \mathrm{cab} / \mathrm{dia}$ ) foi o farelo de milho (fubá), o qual foi utilizado como placebo para o lote controle T1.

A mensuração do consumo de ração e produção de leite das duas ordenhas foram feitas 3 vezes por semana durante a fase experimental.

Os animais foram pesados antes do parto e a cada 28 dias após o parto, considerando também nesta fase o escore da condição corporal (ECC).

Os dados foram analisados pelo método dos Quadrados Mínimos e as diferenças entre médias pelo Método de Tukey (GOMES, 1981).

TABELA 2. Composição do concentrado.

\begin{tabular}{lcc}
\hline & $\mathrm{Kg} / \mathrm{MO}$ & $\% \mathrm{MS}$ \\
\hline Fubá de Milho & 42,0 & 40 \\
Farelo de Soja (40\%) & 15,0 & 13,35 \\
Farelo de Trigo & 12,0 & 10,70 \\
Farelo de Algodão (38\%) & 28,0 & 25,80 \\
Tamponante & 1,8 & 1,62 \\
Mistura Mineral & 1,0 & 0,90 \\
Mistura Vitamínica & 0,2 & 0,18 \\
& $100 \mathrm{~kg}$ & 92,55 \\
\hline \hline
\end{tabular}

\section{RESULTADOS E DISCUSSÃO}

A análise dos dados (TABELA 3 e Gráfico 1) demonstram que o tratamento $T 2$ apresentou durante o período experimental de 112 dias, um aumento médio de produção de leite de $13,5 \%(22,6 \mathrm{x}$ $19,96)$ em relação a T1, e $10 \%(22,66 \times 20,58) \mathrm{em}$ relação a $\mathrm{T} 3$.

Considerando os quatro periodos (TABELA 4 e Gráfico 2) verifica-se que o tratamento T2 resultou em maior produção de leite nos periodos I, II, III e IV, em relaçăo ao tratamento $T 1$, enquanto o tratamento $\mathrm{T} 3$ teve maior produção apenas, no período $\mathrm{I}$. Trabalhando com vacas leiteiras, OLIVEIRA et al.
(1992), constataram também que a dosagem de $300 \mathrm{mg}$ de monensina sódica apresentou melhor resultado quanto à produção de leite. Entretanto, RANDEL \& ROUQUETE (1976) e SPROTT $e t$ al. (1981), não verificaram alteração na produção e composição de leite quando forneceram monensina para vacas de corte.

Com relação ao consumo de ração (TABELA 3 e Gráfico 1) evidencia-se uma ređução média, estatisticamente significante de $4,5 \%$ em relação ao lote $\mathrm{T} 1$, enquanto o lote $\mathrm{T} 3$ teve uma diminuição de 3\%. Resultados similares foram verificados em gado de corte (BERGEN \& BATES, 1984) e em novilhas da raça holandesa (CAMPOS NETO et al., 1983). 
TABELA 3. Médias da produção de leite e consumo de ração durante o período experimental de 112 dias.

\begin{tabular}{|c|c|c|c|}
\hline & \multicolumn{3}{|c|}{ Tratamentos } \\
\hline & $\mathrm{Tl}$ & $\mathrm{T} 2$ & T3 \\
\hline $\begin{array}{l}\text { Monensina sódica } \\
\text { (mg/cab/dia) }\end{array}$ & 0 & 300 & 225 \\
\hline $\begin{array}{l}\text { Produçãa de leite } \\
\text { (kg/cab/dia) }\end{array}$ & $19,96 \mathbf{a}$ & $22,66 b$ & $20,60 a$ \\
\hline $\begin{array}{l}\text { Consumo de raçăo total } \\
\text { (kg/ MS/cab/dia) }\end{array}$ & $20,35 a$ & $19,41 b$ & $19,75 b$ \\
\hline
\end{tabular}

Médias com letras diferentes na mesma linha diferem estatisticamente $(P<0,05)$.

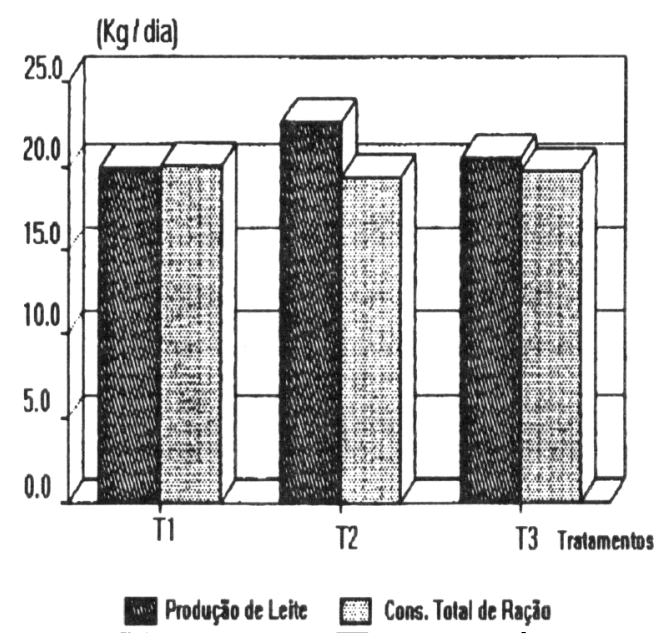

Gráfico 1: Produção de Leite de vacas não tratadas (T1) ou tratadas com Monensina sódica (T2 $300 \mathrm{mg}$ e T3 $225 \mathrm{mg}$ ) durante o periódo experimental de 112 dias.

Verifica-se assim que mesmo com redução do consumo de ração, houve aumento significativo na produção de leite (Tratamento T2), a qual está diretamente associada a utilização da energia metabolizável, proporcionado pelo aumento da proporção molar do ácido propiônico a nível de rúmen (ROWE et al., 1981) que sendo o precursor direto da formação de glicose, atua diretamente na galactopoiese a nível de glândula mamária.

Por outro lado a TABELA 5, que evidencia o escore da condição corporal (ECC), mostra que o lote T2, mesmo apresentando maior produção de leite, teve uma recuperação de peso durante a fase de lactação melhor que o lote T1. Provavelmente a monensina sódica através dos produtos de seu metabolismo promovem com maior eficiência a utilização dos alimentos, ou ainda, devido a alteração do perfil hormonal particiona os nutrientes para fins produtivos.

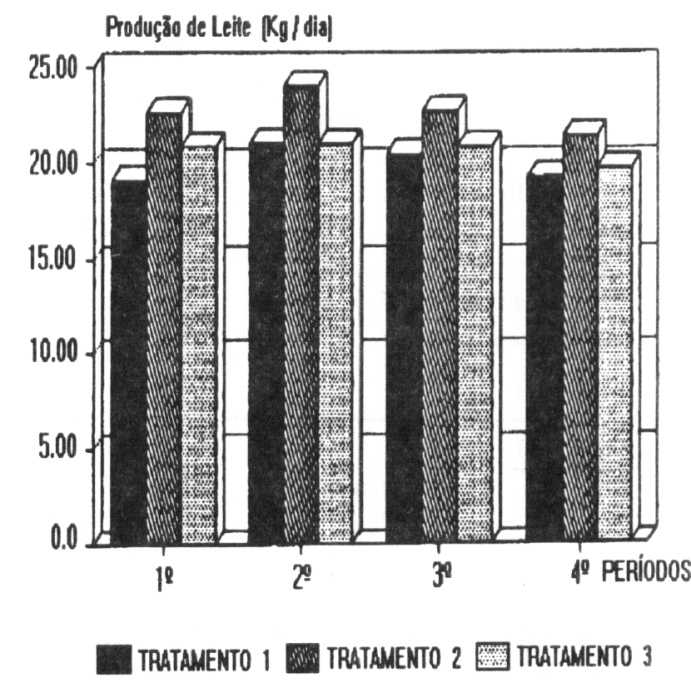

Gráfico 2: Produção de vacas não tratadas (T1) ou tratadas com monensina sódica (T2; 300 $\mathrm{mg} \mathrm{e} \mathrm{T3,225} \mathrm{mg)} \mathrm{durante} \mathrm{os} 4$ períodos do experimento. 
TABELA 4. Médias da produção de leite ( $\mathrm{kg} / \mathrm{cab} / \mathrm{dia})$ durante os quatro periodos do experimento.

\begin{tabular}{ccccc}
\hline \hline & \multicolumn{4}{c}{ Periodos } \\
\cline { 2 - 5 } Tratamentos & $1^{\circ}$ & $2^{\circ}$ & $3^{\circ}$ & $4^{\circ}$ \\
T1 & $19,13 \mathrm{a}$ & $21,02 \mathrm{a}$ & $20,44 \mathrm{a}$ & $19,24 \mathrm{a}$ \\
$\mathrm{T} 2$ & $22,64 \mathrm{~b}$ & $23,99 \mathrm{~b}$ & $22,66 \mathrm{~b}$ & $21,37 \mathrm{~b}$ \\
$\mathrm{~T} 3$ & $20,84 \mathrm{c}$ & $20,98 \mathrm{a}$ & $20,82 \mathrm{a}$ & $19,68 \mathrm{a}$ \\
\hline \hline
\end{tabular}

Médias com letras diferentes na mesma coluna diferem estatisticamente $(\mathrm{P}<0,05)$.

TABELA 5. Escore da condição corporal durante a fase pré e pós parto.

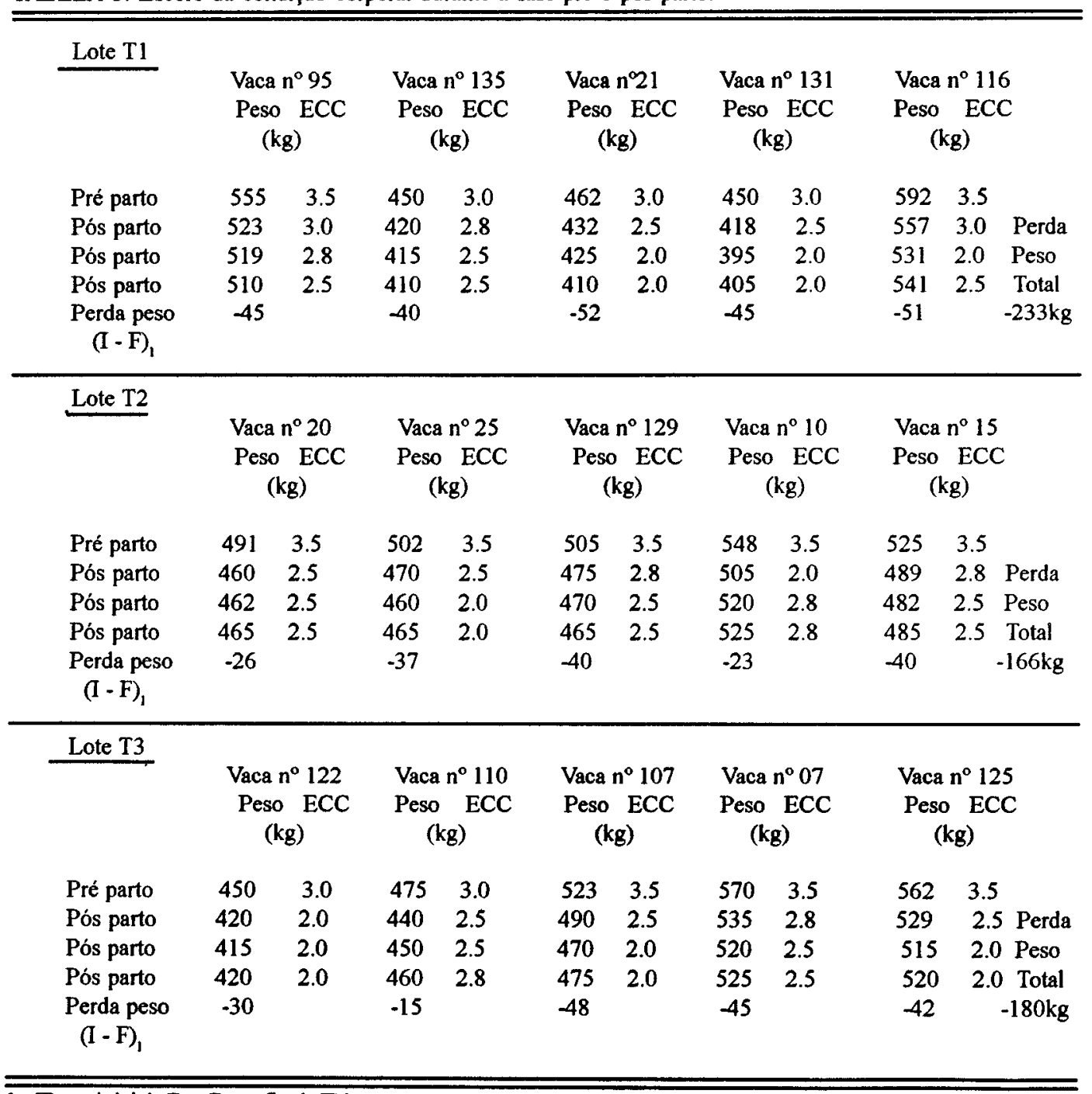

1- [Peso inicial (I) - Peso final (F)].

Sci. agric., Piracicaba, 52(2):268-273, mai./ago. 1995 


\section{CONCLUSÃO}

Diante dos resultados obtidos no presente experimento podemos concluir que a monensina sódica poderá ser utilizada com finalidade galactopoiética em vacas leiteiras.

\section{REFERÊNCIAS BIBLIOGRÁFICAS}

ASSOCIATION OF OFFICIAL AGRICULTURAL CHEMISTS. Omcial methods of analysis. 10.ed., Washington: A.O.A.C., 1965. 957p.

BERGEN, W.G.; BATES, D.B. Ionophores: their effect on production efficiency and mode of action. Joumal of Animal Science, Champaign, v.58, n.61, p 1465-1483, 1984.

BROWN, D L.; HOGUE, D.E. Effects of feeding monensin sodium to lactating goats: milk composition and ruminal volatile fatty acids. Journal of Dairy Science, Champaign, v.68, p.1141-1147, 1985.

CAMPOS NETO, O.; TRONCOSO, H.; PEREZ-GIL, F; BACCARI JÚNIOR, F. Efeito da monensina sódica, olaquindox e metionina hidroxi análogo em novilhas da raça holandesa. In: REUNIÃO DA SOCIEDADE BRASILEIRA DE ZOOTECNIA, 20., 1983. Pelotas. Anals... Pelotas. SBZ, 1983. p.101.

CHEN, M.; WOLIN, M.J. Effect of monensin and lasolocidsodium on the growth of methanogenetic and rumen saccharolytic bacteria. Applied and Environmental Microbiology, Baltimore, v.38, n.1, p.72-77, 1979.

DONOHO, A.L. Biochemical studies on the fate of monensin in animal and in the environment. Joumal of Animal Science, Champaign, v.58, p.1528-1539, 1984.

GOMES, F.P. Curso de estatística experimental. S.ed. Piracicaba: ESALQ, 1981. 389p.
GOODRICH, R.D.; GARRETT, J.E.; GAST, D.R.; KIRICK, M.A. Influence of monensin on the performance of cattle. Journal of Animal Science, Champaign, v.58, n.6, p.1484-1498, 1984.

LEMENAGER, R.P.; OWENS, F.N.; SMOKEY, B.J.; LUSBY, K.S.; TOTUSEK, R. Monensin effect on rumen tumover rate, twenty-four hour VFA pattern, nitrogen components and cellulose disappearance. Journal of Animal Science, Champaign, v.47, n.1, p.255, 1978.

NAGARAJA, T.G.; AVERY, T.B.; BARTLEY, E.E; GALITZER, S.J.; DAYTON, A.D. Prevention of lactic acidosis in cattle by lasolocid or monensin. Journal of Animal Science, Champaign, v.53, n.1, p.206-216, 1981.

OLIVEIRA, M. dal S.; VIEIRA, P.F.; ESCOBAR, M.G.; BARBOSA, J.C.; Utilização da monensina sódica na alimentação de vacas leiteiras. In: REUNIÃO DA SOCIEDADE BRASILEIRA DE ZOOTECNIA, 29., 1992. Lavras. Anals... Lavras: SBZ, 1992. p.168.

RANDEL, R.D.; ROUQUETE JUNIOR, F.M. Effect of monensin on lactation in beef cows. Journal of Animal Sclence, Champaign, v.43, n.1, p.232, 1976.

REARL, L. C. Nutrient requirements of ruminants in developing countries. Intern. Fledst. Institute. Utah State University, Logan. Utah, 1982.

RUSSEL, J.B.; STROBEL, H.J. Effect of iophores on ruminal fermentation. Applied and Environmental Microbiology, Baltimore, v.55, n.1, p.1-6, 1989.

SCHELLING, G.T. Monensin mode of action in the rumen. Joumal of Animal Science, Champaign, v.58, n.6, p.1518-1527, 1984.

SPROTT, L.R.; CURAH, L.R; KIRACOFE, G.H. The effects of rumensin and two levels of energy prior to calving of reproductive performance of first calf heifers. Kansas Agricultural Experiment Station Report of Program, Manhatan, n.394, p.44, 1981.

Recebido para publicação em 01.07 .94

Aceito para publicação em 17.12.94 